\title{
Bir Hidroksiazo Bileşiği Kullanılarak Gerçek Örneklerde Nikelin Eser Miktarlarının Spektrofotometrik Tayini
}

\author{
Tufan GÜRAY*1 (B) \\ ${ }^{1}$ Eskişehir Osmangazi Üniversitesi, Fen Edebiyat Fakültesi, Kimya Bölümü, 26480, Eskişehir, Türkiye
}

(Alınıș / Received: 12.06.2019, Kabul / Accepted: 19.09.2019, Online Yayınlanma / Published Online: 15.12.2019)

\section{Anahtar Kelimeler \\ Nikel, \\ Spektrofotomerik tayin, \\ 2,3,4,6/-tetrahidroksi-3/- sülfoksiazobenzen, THSA}

\begin{abstract}
Özet: Bu makalede, nikel tayini için, herhangi bir ön deriştirme işlemi uygulamadan, pH 5,5 (5-6) 'da 2,3,4,6/-tetrahidroksi-3/-sülfoazobenzen (THSA) ile șelat oluşturarak seçici ve duyarlı bir spektrofotometrik yöntem önerilmiștir. Metal ligand oranı 1: 1 olan kompleksin, $485 \mathrm{~nm}$ 'de, molar absorplama katsayısı 1,60 ×104 $\mathrm{L} \mathrm{mol}^{-1} \mathrm{~cm}^{-1}$ 'dir. Kompleks bileşik 3 saat kararlılığını korumaktadır. Ayrıca, $50^{\circ} \mathrm{C}^{\prime} y e$ kadar bozulmadan kalır. Geliștirilen yöntem 0,040-2,348 $\mu \mathrm{g} \mathrm{mL} \mathrm{mL}^{-1} \mathrm{Ni}$ (II) tayin aralığında Beer'in kanununa uyar. Toprak alkali elementler, alkalin elementler, nadir toprak elementler, halojenürler, fosfatlar, askorbik asit ve katyonlar nikel tayini engellemez. Önerilen yöntem hızlı ve basittir ve nikel tayini için sertifikalı alaşımlara ve çevre suyu örneklerine kolayca uygulanabilir.
\end{abstract}

\section{Spectrophotometric Determination of Trace Amount of Nickel in Real Samples by Using Hydroxyazo Compound}

\section{Keywords}

Nickel,

Spektrophotometric

determination,

2,3,4,6/-Tetrahydroxy-3/-

sulphoazobenzene,

THSA

\begin{abstract}
In this article, a selective and sensitive spectrophotometric by chelating with 2,3,4,6/-tetrahydroxy-3/-sulfoazobenzene (THSA) at $\mathrm{pH} 5.5$ (5-6) without applying any preconcentration process for nickel determination method is proposed. A selective and sensitive spectrophotometric method has been proposed for the determination of nickel by forming chelate at $\mathrm{pH} 5.5$ (5-6) with 2,3,4,6/tetrahydroxy-3/-sulfoazobenzene (THSA). Molar absorptivity of the complex having metal ligand ratio of $1: 1$ is $1.60 \times 10^{4} \mathrm{~L} \mathrm{~mol}^{-1} \mathrm{~cm}^{-1}$ at $485 \mathrm{~nm}$. The complex compound is stable for 3 hours. Furthermore, it is stable up to $50^{\circ} \mathrm{C}$. The developed method obeys Beer's law for 0.040-2.348 $\mu \mathrm{g} \mathrm{mL}^{-1} \mathrm{Ni}(\mathrm{II})$. Earth alkaline elements, alkaline elements, rare earth elements, halides, phosphates, ascorbic acid and cations do not interfere nickel determination. The proposed method is rapid and simple, and it can be easily applied on certificated alloys and environmental water samples for determining nickel.
\end{abstract}

\section{Giriş}

Biyolojik öneme sahip olan nikel, insan beslenmesinde önemli bir iz elementtir. Nikel, bitkiler ve bazı evcil hayvanlar için çok önemli olan üreaz enziminin yapısında bulunan element olması [1] nedeniyle bunların insanlar tarafından tüketilmesinin sonucu olarak önem kazanmaktadır. Nikel, elektro kaplamada, Ni-Cd pillerin imalatında, ark kaynağı çubuklarında, boya pigmentlerinde, seramik, cerrahi ve dental protezlerde, manyetik bantlarda ve bilgisayar bileșenlerinde ve nikel katalizörlerinde yaygin olarak kullanılır [2].
Nikel içeren ürünlerin fazla tüketimi, nikel ve bileșenlerinin üretimi, kullanımı ve imhasında oluşan çevre kirliliği kaçınılmazdır. İnsanlar solunum yoluyla, ağız yoluyla, içme sularıyla, bazı gıdaların tüketimiyle veya sigara içilmesiyle nikele maruz kalabilir. Bu durum, nikel alerjisi, akciğer kanseri, girtlak kanseri ve böbrek hastalıkları gibi önemli rahatsızlıklara yol açmaktadır[3].

Nikelin insan ve çevreye karșı sözü edilen bu etkilerinden dolayı tayini için yeni yöntemlerin geliştirilmesine ihtiyaç duyulmaktadır. $\mathrm{Bu}$ yöntemlerden en kolay, en kısa sürede sonuç veren, en ucuz olan ve uzman gerektirmeyenlerinden biri olan 
UV-görünür bölge spektrofotometresi yöntemidir. Bu cihaz ile yapılan katyon tayinlerinde kullanılan ligandların tayini yapılacak katyona seçici ve hassas olması temel hedeflerdendir. Bu sebepledir ki, bu çalışmada nikel tayini için uygun bir ligand yardımıyla yeni bir yöntem geliştirilmesi amaçlanmıştır.

Nikel için geliştirilen yöntemlerde suda çözünürlüğü yüksek, geniş $\mathrm{pH}$ aralıklarında (özellikle asidik bölgede) kompleks oluşturabilen, seçiciliği yüksek, görünür bölgede absorpsiyon veren, eser miktarlardaki tayini için düşük gözlenebilme sınırı sağlayan ligandlara ihtiyaç duyulmaktadır. Nikel iyonunun ara asit olması, azotun da bir ara baz olması nedeniyle nikel azotlu ligandlarla kompleksleşme yatkınlığındadır [4]. Bu kapsamda nikel tayini için bir hidroksiazo boyar madde olan 2,3,4,6/-tetrahidroksi3/-sülfoksiazobenzen (THSA) [5] (Şekil kullanılmıştır.

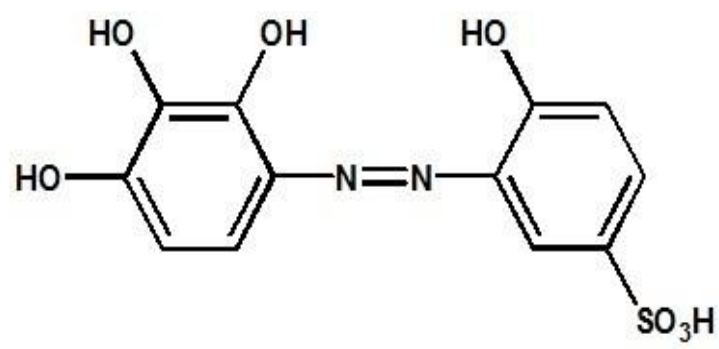

Şekil 1. 2,3,4,6/-tetrahidroksi-3/-sülfoksiazobenzen (THSA)

\section{Materyal ve Metot}

\subsection{Kullanılan kimyasal ve cihazlar}

Standart nikel çözeltisi (ICP 1000mg/L, CertiPUR ${ }^{\circledR}$, Merck) stok çözelti olarak kullanılmıştır. Çalışmada kullanılan nikel çözeltileri, bu stok çözeltinin seyreltilmesi ile hazırlanmıştır. Literatürdeki [5] gibi sentezlenmiş olan, 2,3,4,6/-tetrahidroksi-3/sülfoksiazobenzen (THSA) ligandının 500 mL'lik stok çözeltisi 0,1653 $\pm 0,0005 \mathrm{~g}$ tartılıp gerekli hacimde çözülmesiyle hazırlanmıştır.

Sigma Aldrich tarafından tedarik edilen referans nikel esaslı iki alaşıma (sertifika değerleri nikel/bakır alaşımı, BCBF5693V-51870, \%: $\mathrm{Ni}, 66,58 ; \mathrm{Cu}, 30,48 ; \mathrm{Pb}$, 0,0134; $\mathrm{Mg}, 0,035 ; \mathrm{Al}, 0.086 ; \mathrm{Ti}, 0,063 ; \mathrm{Nb}, 0,156 ; \mathrm{Co}$, 0,029; $\mathrm{Mo}, 0,023 ; \mathrm{Cr}, 0,073 ; \mathrm{Fe}, 1,24 ; \mathrm{Mn}, 1,00 ; \mathrm{P}, 0,0054$; $S$, 0,0069; Si, 0,293; $C, 0,0051$ ve alüminyum/nikel alaşımı, 72240, \%: Al:50; Ni:50) nikel tayini için uygulanmıştır.

Bölgesel çeşme sularında nikel tayini yapılmıştır. Spektrofotometrik ölçümler Unicam 2-UV Spectrometer Double Beam UV-Visible spektrofotometrisi ile yapılmıştır. Bu ölçümlerde 1,00 cm'lik ışık yollu kuvartz hücreler kullanılmıştır. pH ölçümleri için Orion 720 A marka pH-metre ve Orion marka 71-03 model cam elektrot kullanılmıştır. Yöntemin karşılaştırması için Perkin Elmer (USA) marka, dört oyuk katot lamba bölmesi olan, AAnalyst
400 model Atomik Absorpsiyon Spektrometresi kullanılmıştır. Nikel tayini için cihaz; dalga boyu 232 $\mathrm{nm}$, yarık aralığı 1,8/1,35, lamba akımı $30 \mathrm{~mA}$, yanıcı gaz asetilen $(2,34 \mathrm{~L} / \mathrm{dk})$ ve yakıcı gaz olarak hava $(10,00 \mathrm{~L} / \mathrm{dk})$ ayarlanmıştır.

\subsection{Genel yöntem}

25 mL'lik balon joje içine tayin aralığında (0,040-2,348 $\mu \mathrm{g} \mathrm{mL}{ }^{-1}$ ) olacak şekilde nikel çözeltisinden alınmıştır. Üstüne 2,5 mL 1,0×10-3 $\mathrm{mol} \mathrm{L}^{-1}$ (son derişim 10,0×105 M) THSA çözeltisi eklenmiştir. Balon jojenin kalibrasyon çizgisine kadar $\mathrm{pH}^{\prime}$ 5,5 olan tampon çözelti ile tamamlanmıştır. Son olarak, hazırlanan bu çözelti $1 \mathrm{~cm}$ 'lik kuvars UV küvetin içine alınıp, 485 nm'de köre karşı ölçüm alınmıştır.

\subsection{Yöntemin analitik uygulamaları}

\subsubsection{Nikel içerikli alaşımlara uygulaması}

0,1005 $\pm 0,0005 \mathrm{~g}$ tartılan alașım örnekleri, $15 \mathrm{~mL} \mathrm{kral}$ suyu ile çözülmüştür. Çözelti kuruyuncaya kadar ısıtılmıştır. Bu kalıntıya $5 \mathrm{~mL} \mathrm{HCl}$ asit eklenerek tekrar kuruyuncaya kadar ısıtılmıştır. Devamında kalıntı, $100 \mathrm{~mL}$ de iyonize suda çözülmüş [6] ve tayin için kullanılmıştır.

\subsubsection{Su örneklerine uygulaması}

$250 \mathrm{~mL}$ nehir suyu veya kaynak suyu bir beher içine alınmış üstüne $30 \mathrm{~mL}$ derişik $\mathrm{HNO}_{3}$ ve $10 \mathrm{~mL} \mathrm{H} \mathrm{H}_{2}$ (\% 30'luk) organik bileşiklerin uzaklaştırılması için eklenmiştir [7]. Suyun hacminin onda birine düşene kadar ısıtılmıştır. Numunelerin pH'ının istenen değere ayarlanmasından sonra, spektrofotometrik tayin, genel yöntemde (Bölüm 2.2) tarif edildiği gibi yapılmıştır.

\section{Bulgular}

\section{1. pH etkisi}

THSA ligandının nikel ile oluşturduğu kompleks bileşiğin absorbansının pH'a ve dalga boyuna göre değişimi incelenmiştir. $\mathrm{Bu}$ amaçla kompleksin $\mathrm{pH}$ 1'den 11'e kadar hazırlanmış olan tampon çözeltiler içindeki absorbansları ölçülmüştür. 25 mL'lik ölçü balonuna 5,0×10-4 M'lı nikel çözeltisinden $1 \mathrm{~mL}$

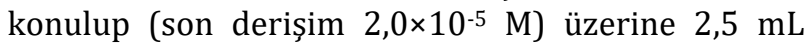

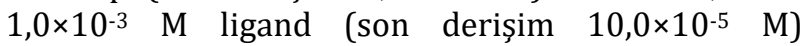
eklendikten sonra, $\mathrm{pH}^{\prime} ı$ ayarlı tampon çözeltiler ile 25 mL'ye tamamlanmıştır. Hazırlanan çözeltilerin pH ayarları yapılmıştır. Karşılaştırma standardı olarak önce suya karşı ve sonrasında standart ligand çözeltisine karşı ölçümler yapılmıştır. Ligand karşılaştırma standardı hazırlanırken 2,5 mL ligand çözeltisi, uygun tampon çözeltisi ile 25 mL'ye tamamlanarak hazırlamıştır. Aynı işlemler diğer tampon çözeltileri kullanılarak tekrar edilmiştir. Ligandın suya karşı, kompleks çözeltisinin suya karşı ve kompleks çözeltisinin ligand karşılaştırma 
standardına karşı ölçümleri alınmıştır. Bu işlemler sonucunda kompleks oluşum pH'nın 5-6 yani 5,5 olarak alınmıştır. Komplekslerin pH'a bağlığı Şekil 2 'de verilmiştir. Bu pH'da gözlenen spektrumdaki kompleksin optimum dalga boyu da $485 \mathrm{~nm}$ olarak belirlenmiştir (Şekil 3).

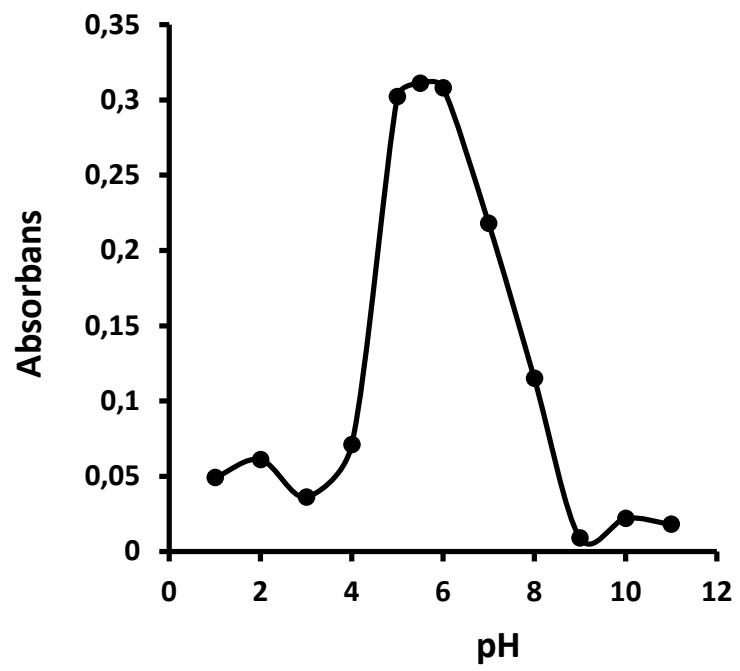

Şekil 2. THSA-Ni kompleksine $\mathrm{pH}$ etkisi $\mathrm{C}_{\text {Nikel }}=2,0 \times 10^{-5} \mathrm{M}$, $\mathrm{C}_{\mathrm{THSA}}=10,0 \times 10^{-5} \mathrm{M}, \mathrm{l}=1 \mathrm{~cm}$.

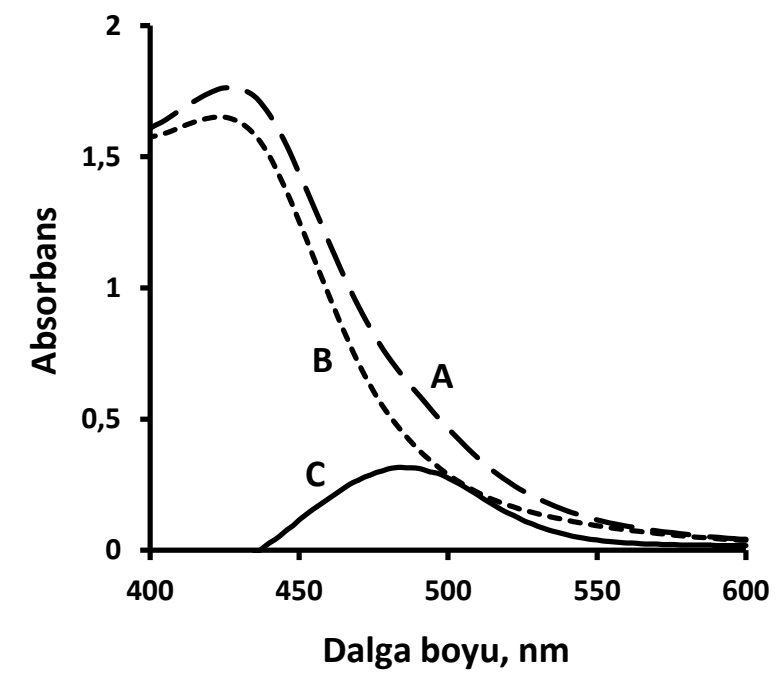

Şekil 3. THSA-Ni kompleksinin suya karşı (A), liganda karşı (C) ve THSA ligandının suya karşı (B) UV-görünür bölge spektrumlarl; $\mathrm{pH}$ : $5,5 \mathrm{C}_{\text {Nikel }}=2,0 \times 10^{-5} \mathrm{M}, \mathrm{C}_{\mathrm{THSA}}=10,0 \times 10^{-5} \mathrm{M}$, $\mathrm{l}=1 \mathrm{~cm}$.

\subsection{THSA ligand konsantrasyonunun etkisi}

Artan miktarlarda THSA ligandı nikel çözeltisine eklendiğinde, nikel-THSA kompleksinin absorbans değerleri artmaya başlamıștır. THSA'nın son derişimi $10,0 \times 10^{-5} \mathrm{~mol} \mathrm{~L}^{-1}$ ve üzeri derişimlerinde $485 \mathrm{~nm}$ 'deki absorbans değerlerinin değişmeden kaldığı gözlenmiştir. Böylece, optimum ligand konsantrasyonu $10,0 \times 10^{-5}$ mol $\mathrm{L}^{-1}$ olarak kullanılmıştır.

\subsection{Ni-THSA kompleks oluşumuna sıcaklık ve zamanın etkisi}

Kompleks bileşik hazırlandığı anda oda sıcaklığında absorbansı ölçülmüştür. Çeşitli zaman aralıklarında tekrar ölçüm alındığında absorbansın en az 3 saat sabit kaldığı gözlenmiştir. Aynı şekilde kompleks bileşik hazırlandığı anda oda sıcaklığında absorbans ölçülmüştür. Sıcaklık arttırılarak farklı sıcaklıklara kadar su banyosunda isıtılıp tekrar oda sıcaklığına soğutulan kompleks bileşiklerin absorbansları tekrar ölçülmüştür. Absorbansların $50 \quad{ }^{\circ}$ C'ye kadar değişmediği $(\Delta \mathrm{A}= \pm 0,03)$, kompleks bileşiklerin bu sıcaklığa kadar dayanıklı oldukları gözlenmiştir. $50{ }^{\circ} \mathrm{C}$ sıcaklığın üzerindeki sıcaklıklarda komplekslerin absorbansları azalmıştır.

\subsection{Kalibrasyon eğrisinin belirlenmesi}

Optimum koşullarda, kalibrasyon eğrisini çizmek için farklı derişimler deki nikel çözeltilerinden alınıp üzerine $1,0 \times 10^{-3} \mathrm{M}$ ligand çözeltisinden 2,5 mL (son

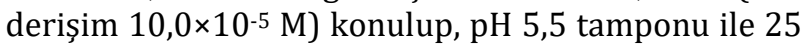
mL' ye seyreltilmiştir. Çözeltilerin absorbansları karşılaştırma standardı olarak ligand çözeltisi alınarak ölçülmüştür. Her ölçüm beş defa tekrarlanmıştır. Bu ölçümlere göre tayin aralığı 0,0402,348 $\mu \mathrm{g} \mathrm{mL} \mathrm{mL}^{-1}$ dır. Molar absorplama katsayısı $1,60 \times 10^{4} \mathrm{~L} \mathrm{~mol}^{-1} \mathrm{~cm}^{-1}$ olarak hesaplanmiștır. Kalibrasyon doğrusunun denklemi de Abs= 0,2204C + $0,0091\left(\mathrm{R}^{2}=0,9990\right)$ olarak bulunmuştur.

\subsection{Kompleks stokiyometrisinin belirlenmesi}

Oluşturulan Ni(II) iyonlu THSA kompleks bileşiğinin stokiyometrisinin belirlenmesinin için Job Yöntemi (izomolar seriler) kullanılmıștır. Bu yöntemde metalligand hacimleri toplamı sabit kalacak şekilde farklı oranlarda alınan $1,0 \times 10^{-3} \mathrm{M}$ ligand ve $1,0 \times 10^{-3} \mathrm{M}$ nikel çözeltileri $25 \mathrm{~mL}$ 'lik bolon jojede $\mathrm{pH}$ 5,5 tamponu ile seyreltilerek optimum koşullarda ölçümler alınmıştır. Bu sonuçlara göre kompleks stokiyometrisi M:L = 1:1 olduğu görülmüştür (Şekil 4).

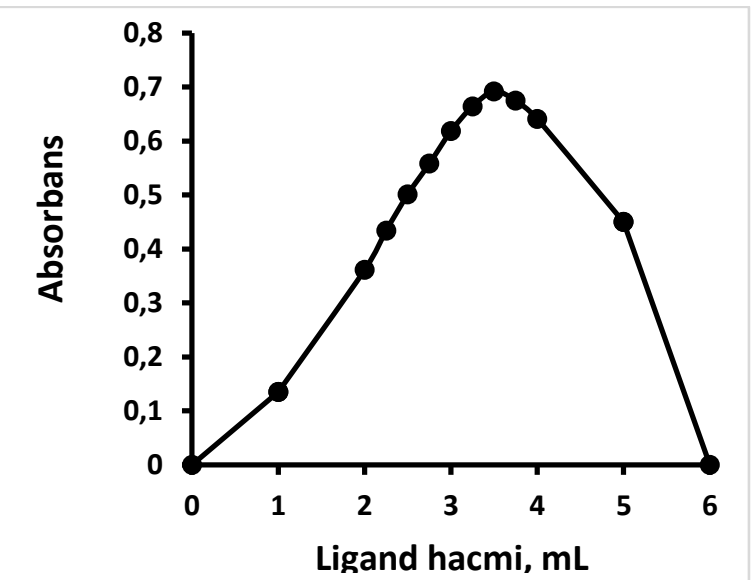

Şekil 4. THSA-Ni kompleksinin Job yöntemi ile kompleks stokiyometrisinin belirlenmesi. $485 \mathrm{~nm}, \mathrm{l}=1, \mathrm{pH}=5,5, \mathrm{C}_{\mathrm{THSA}}=$ $\mathrm{C}_{\text {Nikel }}=1,0 \times 10^{-3} \mathrm{M}$. 


\subsection{Bozucu etki yapan türlerin incelenmesi}

Yöntemin seçiciliği incelenirken, tayin aralığında kalacak şekilde nikel derişimi kullanılarak optimum şartlarda kompleksin absorbansı ölçülmüştür. Daha sonra bozucu etki yapan iyonik ve moleküler türler ortama eklenerek pH ayarı yapılmış ve ölçümler alınmıştır. Kalay $\left(\mathrm{SnCl}_{2}\right)$ dışında, katyonlar genel olarak, nitrat ve sülfat tuzlarından, anyonlarda sodyum ve potasyum tuzlarından hazırlanmıştır. $\mathrm{Bu}$ tuzların 1000'lik ppm stok çözeltilerinden reaksiyon ortamına, çeşitli miktarlarda ilaveler yapılmıştır. Nikelin yanına, azalan miktarlardaki bozucu etki yapan türlerin ayrı ayrı ilavesine bağlı olarak, kompleksleşme sonucu ölçülen absorbans değerleri ile tek başına nikelin ligand ile oluşturduğu kompleksin ölçülen absorbans değeri arasında $\Delta \mathrm{A}_{\max }=$ $\pm 0,05$ olacak şekilde bir aralık belirlenerek, bu türlerin bozucu etki yapıp yapmadıkları belirlenmiştir. Sonuçlar Tablo 1'de verilmiștir.

Tablo 1. Bazı türlerin kompleks oluşumuna etkileri, $\Delta \mathrm{A}_{\max }=$ \pm 0.05 (Alınan $\mathrm{Ni}^{2+}$ miktarl 1,174 $\mu \mathrm{g} \mathrm{mL}-1$ dir.)

\begin{tabular}{|c|c|}
\hline $\begin{array}{c}\text { Bozucu etki yapan } \\
\text { türler }\end{array}$ & $\begin{array}{c}\text { Bozucu etki yapma sınırı } \\
\left(\text { 可 } \mathrm{g} \mathrm{L}^{-1}\right)\end{array}$ \\
\hline CI 1- & $1: 1000$ \\
\hline $\mathrm{Br}^{1-}$ & $1: 1300$ \\
\hline I 1- & $1: 2700$ \\
\hline F 1- & $1: 6100$ \\
\hline $\mathrm{SO}_{4}{ }^{2-}$ & $1: 1500$ \\
\hline $\mathrm{AsO}_{2}^{-}$ & $1: 1000$ \\
\hline $\mathrm{B}_{4} \mathrm{O}_{7}^{2-}$ & $1: 650$ \\
\hline $\mathrm{HPO}_{4}{ }^{2-}$ & $1: 1000$ \\
\hline $\mathrm{C}_{2} \mathrm{O}_{4}{ }^{2-}$ & $1: 650$ \\
\hline $\mathrm{NaF}$ & $1: 5100$ \\
\hline $\mathrm{NH}_{4} \mathrm{~F}$ & $1: 6100$ \\
\hline Tiyoüre & $1: 2000$ \\
\hline $\mathrm{SCN}^{-}$ & $1: 1700$ \\
\hline Tartarik asit & $1: 1000$ \\
\hline Üre & $1: 1700$ \\
\hline $\mathrm{Fe}^{3+}+\mathrm{NaFa}$ & $1: 5$ \\
\hline $\mathrm{Al}^{3+}+\mathrm{NaFa}^{2}$ & $1: 20$ \\
\hline $\mathrm{Cu}^{2+}+\mathrm{Na}_{2} \mathrm{~S}_{2} \mathrm{O}_{3} \mathbf{b}$ & $1: 30$ \\
\hline $\mathrm{Cd}^{2+}+\mathrm{Na}_{2} \mathrm{~S}_{2} \mathrm{O}_{3} \mathbf{b}$ & $1: 100$ \\
\hline $\mathrm{Ca}^{2+}$ & $1: 100$ \\
\hline $\mathrm{Sr}^{2+}$ & $1: 1300$ \\
\hline $\mathrm{Mn}^{2+}$ & $1: 15$ \\
\hline $\mathrm{Cr}^{2+}$ & $1: 15$ \\
\hline $\mathrm{Pb}^{2+}$ & $1: 65$ \\
\hline $\mathrm{Bi}^{3+}$ & $1: 15$ \\
\hline $\mathrm{Hg}^{2+}$ & $1: 2$ \\
\hline $\mathrm{Sn}^{2+}$ & $1: 10$ \\
\hline $\mathrm{Na}^{+}$ & $1: 5000$ \\
\hline $\mathrm{K}^{+}$ & $1: 5000$ \\
\hline $\mathrm{NH}_{4}{ }^{+}$ & $1: 600$ \\
\hline $\mathrm{S}_{2} \mathrm{O}_{3}{ }^{2-}$ & $1: 16$ \\
\hline
\end{tabular}

\subsection{Geliştirilen yöntemin gerçek örneklere uygulaması}

Geliştirilen spektrofotometrik yöntem standart nikel alaşımlarına ve bölgesel su örneklerine başarı ile uygulanmıştır.

$\mathrm{Bu}$ yöntem, nikel bazlı (nikel/bakır alaşımı, BCBF5693V-51870 ve alüminyum/nikel alaşımı,
72240) standart alaşım numunelerinde nikel (II) içeriğinin belirlenmesi için de uygulanmıştır. Her bir çözeltinin uygun miktarları alınıp bölüm 2.2. deki "Genel Yöntem" kullanılarak nikel (II) tayini için uygulanmıştır. Elde edilen sonuçlar, Tablo 2'de verilmiştir.

Uygun miktarlarda alının su örnekleri, bu yöntem ile geliştirilen spektrofotometrik nikel tayinine uygulanmıştır. Elde edilen sonuçlar atomik absorpsiyon spektrometrisi ile bulunan sonuçlar ile karşılaştırılmıştır (Tablo 3).

Tablo 2. Nikel esaslı alașım örneklerinde nikelin spektrofotometrik tayini ( $\mathrm{n}=5, \% 95$ G.S.)

\begin{tabular}{|c|c|c|c|c|}
\hline Örnek & $\begin{array}{c}\text { Sertifika } \\
\text { değeri, } \\
\text { Ni (\%) }\end{array}$ & $\begin{array}{c}\text { Bulunan Ni } \\
\text { (\%) } \\
\text { değeri, } \\
\bar{X} \pm \frac{t s}{\sqrt{n}}\end{array}$ & $\begin{array}{c}\text { S.S., } \\
(s)\end{array}$ & $\begin{array}{l}\text { B.S.S. a , \%, } \\
\text { B.S.S. } \\
=\frac{S}{\bar{X}} x 100\end{array}$ \\
\hline $\mathrm{Ni} / \mathrm{Cu}$ alașımı & 66,58 & $\begin{array}{c}66,26 \pm \\
0,21\end{array}$ & 0,18 & 0,27 \\
\hline $\mathrm{Ni} / \mathrm{Al}$ alaşımı & 50,00 & $\begin{array}{c}50,62 \pm \\
0,62\end{array}$ & 0,54 & 1,07 \\
\hline
\end{tabular}

Tablo 3. Su örneklerinde nikelin geliştirilen UV-görünür spektrofotometrik yöntem ve atomik absorpsiyon spektrometrisi (AAS) ile tayinin karşılaștırılması

\begin{tabular}{|c|c|c|c|}
\hline \multicolumn{2}{|l|}{ Örnek } & $\begin{array}{l}\text { Geliştirilen } \\
\text { UV-Gör. Spek. } \\
\text { Yöntemi } \\
(n=5, \% 95 \text { G.S.) }\end{array}$ & $\begin{array}{lr}\text { AAS } & \text { yöntemi } \\
(n=5, \quad \% 95 \\
\text { G.S.) }\end{array}$ \\
\hline & $\bar{X}\left(\mu \mathrm{mL}^{-1}\right)$ & 0,561 & 0,496 \\
\hline Nehir & S.S., $(s)$ & 0,009 & 0,011 \\
\hline \multirow[t]{2}{*}{ suyu } & B.S.S. ${ }^{a}, \%$ & 1,604 & 2,218 \\
\hline & G.S. $(p=0.05)^{\mathrm{b}}$ & $0,561 \pm 0.010$ & $0,496 \pm 0.013$ \\
\hline & $\bar{X}\left(\mu \mathrm{g} \mathrm{mL} L^{-1}\right)$ & 0,956 & 0,922 \\
\hline Kuyu & S.S., $(s)$ & 0,005 & 0,006 \\
\hline \multirow[t]{2}{*}{ suyu } & B.S.S. ${ }^{a}, \%$ & 0,523 & 0,651 \\
\hline & G.S. $(p=0.05)^{\mathrm{b}}$ & $0,956 \pm 0,005$ & $0,922 \pm 0,006$ \\
\hline . & $x 100$ & & \\
\hline b \%95 & $=\bar{X} \pm \frac{t s}{\sqrt{N}}$ & & \\
\hline
\end{tabular}

\section{Tartışma ve Sonuç}

Yeni bir UV-Görünür spektrofotometrik nikel tayini yöntemi geliştirilmiştir. Nikel derişiminin 0,040-2,348 $\mu \mathrm{g} \mathrm{m}^{-1}$ olduğu tayin aralığında yöntem Lambert-Beer yasasına uygunluk göstermiştir. Ni-THSA kompleksinin molar absorplama katsayısı (M:L; 1:1) $1,60 \times 10^{4} \mathrm{~L} \mathrm{~mol}^{-1} \mathrm{~cm}^{-1}$ olarak hesaplanmıştır. Geliştirilen bu yeni yöntemin nispeten seçici ve hassas olduğu gözlenmiştir. Yöntemin seçiciliği için kullanılan yabancı iyon türlerinden büyük bir kısmının, geliştirilen yönteme etki etmediği belirlenmiștir. Bu çalışmada, THSA ligandı ile yapılan tayinde, herhangi bir ön ayırma tekniği kullanılmamıștır. Yöntemin seçiciliği ve hassasiyetini arttırmak için herhangi bir yüzey aktif maddeye ihtiyaç duyulmamıştır. Geliştirilen yöntemin karşılaştırması son birkaç yıldaki benzer çalışmalar dikkate alınarak Tablo 4'te verilmiştir. Sonuç olarak, önerilen yöntemin nikel tayini için basit, tekrarlanabilir, kolay ve hassas olduğu ortaya konmuştur. Ayrıca, geliştirilen bu yeni yöntem, nikelin 
tayini için sertifikalı alaşımlara ve su örneklerine başarıyla uygulanabilmiştir. $\mathrm{Bu}$ bakımdan

Tablo 4. Son bir kaç yılda literatürde bildirilen nikelin spektrofotometrik tayin yöntemlerinin bazı özelliklerinin karşılaştırılması

\begin{tabular}{|c|c|c|c|c|c|}
\hline Reaktif & $\mathrm{pH}$ & $\begin{array}{c}\mathcal{E} \\
\left(\mathrm{L} \mathrm{mol}^{-1}\right. \\
\left.\mathrm{cm}^{-1}\right)\end{array}$ & $\begin{array}{c}\text { Tayin } \\
\text { aralıkları } \\
\left(\mu \mathrm{g} \mathrm{mL}^{-1}\right)\end{array}$ & $\begin{array}{c}\text { Yöntemlerin dikkat çekici } \\
\text { noktaları }\end{array}$ & Kaynak \\
\hline $\begin{array}{l}\text { 5-metil-2-asetilfuran-4- } \\
\text { metil-3-tiyosemikarbazone } \\
\text { (5-MAFMT) }\end{array}$ & 9,5 & $1,87 \times 10^{4}$ & $\begin{array}{l}0,060- \\
0,600\end{array}$ & $\begin{array}{l}\text { 1-Yüksek pH nedeniyle katyonların } \\
\text { çökme riski var. }\end{array}$ & [8] \\
\hline $\begin{array}{c}\text { Nikotinohidroksamik asit } \\
\text { (NHA) }\end{array}$ & 9,0 & $1,37 \times 10^{4}$ & $\begin{array}{l}0,430- \\
8,560\end{array}$ & $\begin{array}{l}\text { 1-Yüksek pH nedeniyle katyonların } \\
\text { çökme riski var. 2-Hassasiyeti } \\
\text { arttırmak için yüzey aktif madde } \\
\text { kullanılmıştır. }\end{array}$ & [9] \\
\hline $\begin{array}{c}\mathrm{N}, \mathrm{N}^{\prime} \text {-bis(4- } \\
\text { metoksisalisiliden) } \\
\text { etilendiamin }\end{array}$ & - & $0,65 \times 10^{4}$ & $\begin{array}{l}0,250- \\
1,500\end{array}$ & $\begin{array}{l}\text { 1-Yöntemin hassasiyeti düşüktür. } \\
\text { 2-Kompleks ortamında çözücü } \\
\text { olarak n-hekzan ve aseton karışımı } \\
\text { kullanılmıştır. }\end{array}$ & [10] \\
\hline $\begin{array}{c}\mathrm{N} \text { '-(2- } \\
\text { hidroksibenzilidene)-3-(4-o- } \\
\text { tolilpiperazin-1-yl) } \\
\text { propanehidrazide (HTP) }\end{array}$ & 9,0 & $0,72 \times 10^{4}$ & $\begin{array}{l}1,170- \\
12,910\end{array}$ & $\begin{array}{c}\text { 1-Yüksek pH nedeniyle katyonların } \\
\text { çökme riski var. 2-Yöntemin } \\
\text { hassasiyeti düşüktür. }\end{array}$ & [11] \\
\hline $\begin{array}{l}\text { 4-hidroksi-3-thiolbenzoic } \\
\text { asit (HTBA) ve } \\
\text { difenilguanidinden (DPG) }\end{array}$ & $\begin{array}{l}4,2- \\
5,8\end{array}$ & $3,35 \times 10^{4}$ & $\begin{array}{l}0,100- \\
12,000\end{array}$ & $\begin{array}{l}\text { 1-Kompleks oluşumu için ikili ligand } \\
\text { karışımı kullanmışlardır. }\end{array}$ & [12] \\
\hline $\begin{array}{l}\text { 1-[(5-benzil-1,3-tiyazol-2- } \\
\text { il)diazenil]naftalen-2-ol } \\
\text { (BnTAN) }\end{array}$ & 5,5 & $1,56 \times 10^{4}$ & $\begin{array}{c}0,006- \\
0,073\end{array}$ & $\begin{array}{l}\text { 1-Ligand çözücüsü olarak etanol } \\
\text { kullanılmıştır. } \\
\text { 2-Yüzey aktif madde kullanılarak } \\
\text { ekstraksiyon yapılmıştır. } \\
\text { 1-Asidik bölgede analiz. }\end{array}$ & [13] \\
\hline $\begin{array}{c}\text { 2,3,4,6/-tetrahidroksi-3/- } \\
\text { sülfoksiazobenzen (THSA) }\end{array}$ & 5,5 & $1,60 \times 10^{4}$ & $\begin{array}{l}0,040- \\
2,348\end{array}$ & $\begin{array}{l}\text { 2-Ligand çözücüsü sudur. } \\
\text { 3-Herhangi ekstraksiyon işlemi } \\
\text { gerektirmez. }\end{array}$ & $\begin{array}{c}\text { Yeni } \\
\text { Yöntem }\end{array}$ \\
\hline
\end{tabular}

\section{Kaynakça}

[1] Zerner, B., 1991. Recent advances in the chemistry of an old enzyme, ureas, Bioorganic Chemistry, 19, 116-131.

[2] Merian, E., Anke, M., Stoppler, M. 2004. Elements and their compounds in the environment. WILEY VCH Weinheim, $116 \mathrm{~s}$.

[3] Kasprzak, K.S., Sunderman, F.W., Salnikow, K. 2003. Nickel carcinogenesis. Mutation Research/Fundamental and Molecular Mechanisms of Mutagenesis, 533 (1-2), 67-97.

[4] Tunalı, N.M., Özkar, S. 1997. Anorganik kimya, Gazi Üniversitesi Yayın No: 185, İkinci Baskı, Fen Edebiyat Fakültesi, Ankara, Türkiye, 250 s.,

[5] Güray, T., Öğretir C., Gedikbey, T., Hüseyinli, A. A. 2011. Synthesis and spectrophotometric determination of acidity constants of 2,3,4,6/tetrahydroxy-3/-sulfoazobenzene and their use in determination of aluminum. Turkish Journal of Chemistry, 35, 291-305.

[6] Ramachandraiah, C., Kumar J. R., Reddy, K. J., Narayana, S. L., Reddy A. V. 2008. Development of a highly sensitive extractive spectrophotometric method for the determination of nickel(II) from environmental matrices using N-ethyl-3carbazolecarboxaldehyde-3-thiosemicarbazone.
Journal of Environmental Management, 88(4),729-736.

[7] Ghaedi M. 2007. Selective and sensitized spectrophotometric determination of trace amounts of $\mathrm{Ni}(\mathrm{II})$ ion using -benzyl dioxime in surfactant media. Spectrochimica Acta Part A, 66(2), 295-301.

[8] Weldeabzgi, A., Reddy, D. N., Mekonnen, K. N. 2017. Spectrophotometric determination of nickel(II) in soil and standard alloy samples using 5-methyl-2-acetylfuran-4-methyl-3-

thiosemicarbazone (5-MAFMT). Journal Communications in Soil Science and Plant Analysis, 48(4), 439-448.

[9] Muthuselvi, R. 2017. Determination of nickel (II) by spectrophotometry in micellar media. Pharmaceutical Analytical Chemistry: Open Access, 3(3), 1-4.

[10] Tokay, F. 2017. Development of UV-Vis. spectrophotometric method for rapid nickel determination in original oil matrix. Süleyman Demirel University Journal of Natural and Applied Sciences, 21(2), 332-337.

[11] Ravichandran, C., Benzil, D., Ramachandraiah C., Chandrasekha K. B. 2015. Extraction and spectrophotometric determination of nickel in water, alloys and edible oil samples. 
International Journal of Bioassays, 4(11), 44684472.

[12] Zalov, A. Z., Kuliev, K. A., Shiralieva, S.M., Askerova, Z. Q. 2018. Extraction spectrophotometric study on the complex formation in the nickel (II)- 4-hydroxy-3thiolbenzoic acid - diphenylguanidine system, Indo American Journal of Pharmaceutical Sciences, 5(12), 15681-15689.
[13] Bazel, Y., Tupys, A., Ostapiuk, Y., Tymoshuk, O., Matiychuk, V. 2017. A green cloud-point microextraction method for spectrophotometric determination of $\mathrm{Ni}(\mathrm{II})$ ions with 1-[(5-benzyl1,3-thiazol-2-yl)diazenyl] naphthalene-2-ol. Journal of Molecular Liquids, 242, 471-477. 